\title{
Analysis of Ground Settlement Caused by Double- line TBM Tunnelling under Existing Building
}

Dongxue Hao ( $\nabla$ haodongxue2005@126.com )

Northeast Electric Power University https://orcid.org/0000-0002-5878-5790

\section{Renjun Zhu}

Northeast Electric Power University

$\mathrm{Ke} \mathrm{Wu}$

Shandong University

\section{Rong Chen}

Northeast Electric Power University

\section{Research Article}

Keywords: TBM tunnelling, crossing building, numerical simulation, ground settlement analysis

Posted Date: June 22nd, 2021

DOl: https://doi.org/10.21203/rs.3.rs-191130/v1

License: (c) (i) This work is licensed under a Creative Commons Attribution 4.0 International License. Read Full License

Version of Record: A version of this preprint was published at Geotechnical and Geological Engineering on July 10th, 2021. See the published version at https://doi.org/10.1007/s10706-021-01934-5. 


\section{Abstract}

TBM tunnelling is less used in the subway construction in prosperous city due to the limitation of the engineering geological conditions. The studies on the influence of the TBM construction on the existing buildings are also limited. Therefore, based on the engineering case of tunnel crossing existing building in the section of Haiboqiao Xiaocunzhuang station of Qingdao Metro Line 1, the numerical model that simulates the construction process of TBM tunnelling in slightly weathered granite layer is established by three-dimensional finite difference software $F L A C^{3 D}$ to analyze the influence of TBM tunneling on ground settlement. The comparisons of ground deformations obtained from FLAC ${ }^{3 \mathrm{D}}$ and field monitoring in different construction stages of double-line tunnel have been made firstly to validate the numerical model. Then the ground settlement characteristics, differential settlement and the stress distribution of the existing building and the stress of segment structure have been analyzed. Ground settlement groove along the transverse and vertical sections occurs near the building and tunnels, and the settlement becomes smaller with the farther distance from them. The settlement curve on the cross section changes dynamically and is approximately V-shaped, and its width is about $5 \sim 6$ times diameter of the tunnel. For the same cross section, the range of the settlement groove after tunnelling right line increases obviously compared with that after tunnelling left line (construction first), the settlement values also increase, and the symmetrical axis of the settlement curve is shifted to the right. This paper can provide important practical reference for relative construction engineering.

\section{Introduction}

Urban underground space has been being developed and utilized with the acceleration of urbanization in recent decades. At present, urban subway has stepped into a high-speed development stage in China ${ }^{[1-3]}$. However, the construction of subway tunnels will inevitably cause the ground and underground soil disturbances and deformation ${ }^{[4-6]}$, which will induce cracks of buildings ${ }^{[7-9]}$, especially for the buildings above the tunnels. It is important to predict the influence of tunnelling on ground deformation and the building stress. Peck ${ }^{[10]}$ proposed early the concept of stratum loss and the prediction formula of the transverse ground deformation caused by the tunnel excavation based on the statistics of the measured data of the shield construction of metro tunnel, namely peck curve. Chen Chunlai et al. ${ }^{[11]}$ studied the calculation approaching of the three-dimensional soil settlement caused by ground loss during doubleline parallel shield tunnel (DLPST) construction based on Peck formula, and established the modified three-dimensional Peck formula considering the influence of first tunnel construction on second tunnel and different excavation positions of two tunnels. Wei Gang et al. ${ }^{[12]}$ established a modified calculation formula of the ground settlement caused by the construction of the short distance double-line parallel shield tunnel based on the stochastic medium theory of single tunnel and considering the asymmetry of the curve caused by the excavation of the first tunnel, which is used to calculate the ground settlement caused by adjacent level parallel twin shield tunnel construction. 
Besides the ground displacement induced by tunnel excavations, it is still focused on that the mutual influences of the tunnel construction and ground surface buildings in urban area. Mroueh et al ${ }^{[13]}$ used a three-dimensional numerical method to compare and analyze the ground settlement displacement of existing buildings and non-existing buildings in the process of tunnel construction. It is found that the internal force distribution of the tunnel is closely related to the stiffness and self-weight of the existing buildings. Jiang Xinliang et al. ${ }^{[14]}$ performed FEM analysis of the tunnel-soil-structure interaction to investigate the differential settlement and variation of internal force due to the passage of a shield tunnel by taking a frame structure office building as the research object and regarding the building and its foundation with cavern as a whole. Jiang Xiaoting et al. ${ }^{[15]}$ analyzed the influence of shield tunnel construction on the surface settlement and the differential settlement of multi-layer masonry structure in Tianjin soft soil area according to the construction of Tianjin Metro Line 2 passing under a masonry building. Jenck et al. ${ }^{[16]}$ considered stratum loss to study the influence of the building's stiffness on ground surface settlement based on numerical simulation software FLAC ${ }^{3 \mathrm{D}}$. Zhang Dingli et al. ${ }^{[17]}$ expounded the deformation mechanism of ground buildings and its failure modes based on the practical case of Xiamen Airport Road Tunnel going through complex building blocks by using in-situ measured data, numerical simulation and theoretical analysis method, proposed the subsequently control standard involving differential subsidence and crack space of buildings and the three-class management method of "early warning, warning and utmost warning" for building deformation, and presented the relationship between building crack space and differential subsidence. Shen Xingzhu et al. ${ }^{[18]}$ took shield tunnel passing through buildings in Shenzhen Metro 7th Line Project for example to investigate the buildings' differential settlement and variation of internal force by using numerical simulation and field monitoring data. Zhang Wenting et al. ${ }^{[19]}$ studied the dynamic coupling effect between ground surface and building during tunnel excavation based on the construction engineering of Qingdao Metro Line 3. And the interaction of deformation between them was analyzed by combining numerical analysis and site monitoring. Lu Ping et al. ${ }^{[20]}$ analyzed the settlement and inclination of the buildings based on shield tunnelling of the Tianjin Metro Line 3 when adopting two crossing modes, i.e. former tunnel underneath crossing + latter tunnel laterally crossing and former tunnel laterally crossing + latter tunnel underneath crossing.

In the above literatures, the subway tunnel engineering is in soil conditions and adopts the shield method. The TBM method is less used in the subway construction of the prosperous city due to the limitation of the engineering geological conditions. Thus the articles about the influence of the TBM construction on the existing building are also less. Based on TBM crossing existing building in the section of haiboqiao xiaocunzhuang station of Qingdao Metro Line 1, this paper adopts three-dimensional finite difference software $F L A C^{3 D}$ to simulate the construction process of TBM double-line tunnel in slightly weathered granite layer and combines with the site monitoring data to investigate the ground surface settlement, the stress and deformation characteristics of the existing building caused by TBM in different excavation stage, which can provide some reference for other TBM construction engineering in prosperous city. 


\section{Engineering Background}

The section of Qingdao Metro Line 1 from Haiboqiao to Xiaocunzhuang Station is plotted in red long arrow in the map below (Fig. 1), which is along Renmin Road in downtown district. The length of left line tunnel is $1061.119 \mathrm{~m}$, with mileage number ZSK39 $+491.675 \sim$ ZSK40 +553.150 , and the right line length is $1061.475 \mathrm{~m}$, YSK39 $+491.675 \sim$ YSK40 +553.150 . There are many old residential buildings and shops on both sides of Renmin road, which are near to Metro Line 1, especially the construction of the left line tunnel crosses the double-layer brick concrete structure house (as shown in the red dotted box in Fig. 1), which might be under threat during tunnelling.

Figure 2 shows the tunnel-house location and stratum distribution. The main strata in the undercrossing area from top to bottom are as follows: \plain and miscellaneous fill: brown yellow, plastic $\sim$ hard plastic, slightly wet, loose, mainly composed of cohesive soil and sand, mixed with a small amount of broken bricks and gravel locally; 『silty clay: brownish yellow to yellowish brown, soft plastic to plastic, with medium compressibility, locally containing silty clay interlayer and lens; 『clayey gravel sand: yellowish brown, saturated, partially mixed with more granitic weathering debris, part of the clayey soil cementitious, containing $5 \sim 35 \%$ clayey soil; $₫$ strongly weathered granite: brown yellow, red flesh, the rock mass is soil columnar to clastic, and sandy by hand, slightly plastic after soaking, well-developed weathering fissures, defined as extremely broken soft rock; \moderately weathered granite: flesh color, medium coarse grain structure, block-like structure, rock mass is fragmented $\sim$ block-like, local immersion is obvious, weathered fissures developed; $₫$ slightly weathered granite: flesh color, the rock cores are mostly short columnar to columnar, containing a small amount of fragmentation, weathered fractures slightly developed, defined as hard rock. The groundwater types are mainly quaternary pore water and bedrock fracture water, the quaternary pore water mainly occurs in alluvial-diluvial sandy soil, residual gravel clay soil and gravel soil, and the bedrock fracture water occurs in strongly weathered granite, moderately weathered granite and slightly weathered granite.

The tunnel in this section is excavated from south to north along Renmin Road (along arrow direction). The buried depth of the subway tunnel $h$ is $19 \mathrm{~m}$. The center line spacing of the double-line parallel tunnel is $14 \mathrm{~m}$. The inner diameter $d$ of lining segment is $5.4 \mathrm{~m}$, outer diameter $D$ is $6.0 \mathrm{~m}$, segment thickness $b=$ $0.3 \mathrm{~m}$, and concrete strength grade is $\mathrm{C} 50$. The excavated stratum is slightly weathered granite with hard rock, which is suitable for the TBM. Therefore, the TBM hard rock tunnelling machine with double shield is adopted to carry out the tunnel excavation with high driving efficiency, good excavation quality and small disturbance to the rock layer.

\section{Numerical Simulation}

\subsection{Numerical model}

The finite difference software FLAC ${ }^{3 \mathrm{D}}$ is used to establish the three-dimensional computational model, shown as Fig. 3. The cross section of the tunnel is XOY plane, and TBM tunnels are along Z axis. 
According to literature [21] and [22], the influence area of tunnel excavation is $3 D-5 D$, so the calculation area of the numerical model is taken as $60 \mathrm{~m}$ horizontally and $25 \mathrm{~m}$ from the bottom of the tunnel vertically. The size of the stratum model is $72 \mathrm{~m} \times 60 \mathrm{~m} \times 50 \mathrm{~m}$ (length $\times$ width $\times$ height). The top of the model is ground surface and building, which is taken as the free boundary. The lateral boundaries are restricted by the horizontal displacements, and the bottom boundary is constrained by the vertical and horizontal displacement. The tunnel is circular, buried at $19 \mathrm{~m}$. Single layer lining is adopted for it. The building size is $24 \mathrm{~m} \times 7 \mathrm{~m} \times 8 \mathrm{~m}$ (length $\times$ width $\times$ height) and its foundation is buried at $1.5 \mathrm{~m}$. Each floor height is 4 meters, and the opening sizes of doors and windows are $2.2 \mathrm{~m} \times 1.8 \mathrm{~m}$ and $1.5 \mathrm{~m} \times 1.8 \mathrm{~m}$ respectively. The linear elastic constitutive model is used for lining segment, grouted soil layer and the building, and Mohr Coulomb elastic-perfectly plastic model is used for the surrounding soil layer. Solid elements are selected for the building, soil and grouting soil. The lining segment is applied after TBM excavation, and simulated by shell element. The model is meshed into 57520 elements and 62128 nodes.

\subsection{Constitutive model and parameters}

Mohr-Coulomb elastic-perfectly-plastic model is used for each stratum soil or rock and elastic model is used for lining segments, grouting soil, superstructure, and foundation. The calculation parameters according to the geological exploration report and the corresponding numerical simulation experience are listed in Table 1. 
Table 1

Material Parameter Values

\begin{tabular}{|c|c|c|c|c|c|c|c|}
\hline Material & $\begin{array}{l}\text { Modulus } \\
\text { (MPa) }\end{array}$ & $\begin{array}{l}\text { Poisson's } \\
\text { ratio }\end{array}$ & $\begin{array}{l}\begin{array}{l}\text { Natural } \\
\text { density }\end{array} \\
(\mathrm{kg} / \mathrm{m} \\
\left.3^{3}\right)\end{array}$ & $\begin{array}{l}\text { Cohesion } \\
(\mathrm{kPa})\end{array}$ & $\begin{array}{l}\text { Friction } \\
\text { angle }\left({ }^{\circ}\right)\end{array}$ & $\begin{array}{l}\text { Thickness } \\
\text { (m) }\end{array}$ & $\begin{array}{l}\text { Model } \\
\text { type }\end{array}$ \\
\hline $\begin{array}{l}\text { Plain and } \\
\text { miscellaneous } \\
\text { fill }\end{array}$ & 19.5 & 0.35 & 1600 & 18 & 15 & 3 & $M-C$ \\
\hline Silty clay & 26 & 0.32 & 1750 & 20 & 22 & 3 & $M-C$ \\
\hline $\begin{array}{l}\text { Clayey gravelly } \\
\text { sand }\end{array}$ & 38 & 0.30 & 1860 & 26 & 22 & 2 & $M-C$ \\
\hline $\begin{array}{l}\text { Strongly } \\
\text { weathered } \\
\text { granite }\end{array}$ & 240 & 0.28 & 1960 & 28 & 23 & 8 & $M-C$ \\
\hline $\begin{array}{l}\text { Moderately } \\
\text { weathered } \\
\text { granite }\end{array}$ & 420 & 0.26 & 2200 & 45 & 25 & 3 & $M-C$ \\
\hline $\begin{array}{l}\text { Slightly } \\
\text { weathered } \\
\text { granite }\end{array}$ & 550 & 0.25 & 2400 & 60 & 35 & 31 & $M-C$ \\
\hline $\begin{array}{l}\text { Lining } \\
\text { segments }\end{array}$ & 31680 & 0.20 & 2500 & / & I & 0.3 & Elasticity \\
\hline Grouting soil & 3000 & 0.20 & 2500 & l & l & 0.2 & Elasticity \\
\hline Superstructure & 24000 & 0.20 & 2500 & / & l & / & Elasticity \\
\hline Foundation & 35000 & 0.20 & 2500 & / & / & 1.5 & Elasticity \\
\hline
\end{tabular}

\subsection{Numerical simulation of construction step}

Gravity load is applied by way of self-weight first, and the displacement of soil under the action of selfweight is removed by geostatic stress balance. The site monitoring data display that the ground surface and the building have different degrees of settlement before excavation. In order to simulate the settlement more accurately, uniform pressure of $45 \mathrm{kPa}$ is applied on the ground floor of the building and uniform pressure of $25 \mathrm{kPa}$ is applied on other the ground surface areas. The width of each 4 lining segments excavated by TBM is taken as a cycle $(6 \mathrm{~m})$, and then the excavation is divided into 12 cycles. The construction and excavation process is as follows:

- Excavate the soil within the scope of grouting circle to $6 \mathrm{~m}$ (a cycle); 
- Apply uniform pressure of 0.3 MPa on the tunnel face to simulate the support pressure from the crust of machine body during TBM excavation;

- Tunnel another cycle (6 m) and apply 0.3 MPa support pressure simultaneously;

- Install the lining segments for the tunnel of the previous cycle;

- Remove the support pressure from the crust of previous cycle to simulate ground loss caused by the gap at the end of TBM excavation, and conduct grouting synchronously;

- Excavate circularly till the tunnel breaks through. Excavate right line tunnel after left line.

\section{Monitoring Data And Verification Of Numerical Results}

The settlement of the building during TBM tunnelling is monitored to ensure the safety and stability of the building. Several monitoring points are arranged around the existing building, among which the most representative 3 monitoring points (ZJC17 19) are selected for the comparison with numerical results, as shown in Fig. 4. The measured and simulated settlement values of each monitoring point are plotted in Fig. 5, where 51 and 66 ring represents the moment that TBM cutter head is driven below the both ends of the existing building respectively.

As can be seen from Fig. 5, the overall settlement of the existing building presents an increasing trend, where the maximum measured value is $5.45 \mathrm{~mm}$ and the simulated settlement is $6.85 \mathrm{~mm}$ during the excavation through the building. The comparison of the measured and simulated settlements shows that the simulated results can basically reflect the actual situation, the simulation process and the parameters used are reasonable. The measured differential settlement is $1.42 \mathrm{~mm}$ and the simulated value is $1.99 \mathrm{~mm}$ when excavation is just passing through the building. The maximum measured differential settlement is $1.58 \mathrm{~mm}$ when the tunnel is excavated directly below the building; correspondingly, the simulated value is $2.1 \mathrm{~mm}$. And when TBM crosses to the end of the building, differential settlement of the building shows a downward trend, the measured value is $0.86 \mathrm{~mm}$.

In the process of TBM tunnelling, whether the existing structures within the affected range are safe or not needs to be judged according to relevant deformation control standards. According to "Code for design of building foundation (GB50007-2011)", the whole settlement $s$ and differential settlement $\Delta s$ of the building should meet the formula (1) considering the actual stratum soil and building condition,

$\int s \leq 30 \mathrm{~mm}$

$\{\Delta s \leq \min \{0.001 L, s\}$

Where is the length or width of building foundation, $\mathrm{m}$. 
According to the actual monitoring data of this project, the maximum settlement of the building $s=$ $5.45 \mathrm{~mm}<30 \mathrm{~mm}, \Delta s=1.58 \mathrm{~mm}<\min \{0.001 \mathrm{~L}, s\}=7 \mathrm{~mm}$. Therefore, the deformation of the building passed through by TBM meets the control standards of relevant codes.

\section{Numerical Results Analysis}

In order to analyze the stress distribution of soils and structures and the surface settlement characteristics caused by TBM tunnelling, three observation sections (Cross Sect. $1 \sim$ Cross Sect. 3) during six construction stages have been analyzed as key points. Construction stage 1 : The left tunnel is driven to about $24 \mathrm{~m}$ where TBM is just crossing the building. Construction stage 2: The left tunnel is driven to about $48 \mathrm{~m}$ where TBM is located at the end of the building. Construction stage 3: The left tunnel is driven to about $72 \mathrm{~m}$, that is, the left tunnel is completed. Construction stage 4: The right tunnel is driven to about $24 \mathrm{~m}$, paralleling to construction stage 1 . Stage 5 : The right tunnel is driven to about 48 $\mathrm{m}$, paralleling to construction stage 2 . Stage 6 : The right tunnel is driven to about $72 \mathrm{~m}$, paralleling to construction stage 3 . The locations of building, tunnels and cross sections are shown in Fig. 4 .

\subsection{Internal force analysis of segment lining}

Since the left line tunnel passes through the existing building, the internal forces of the segment lining of the left line tunnel is analyzed after the constructions of left and right tunnels respectively. Figure 6 and Fig. 7 show the axial force and bending moment of the segment lining at cross Sect. 2. It can be seen from Fig. 6 (a) that the larger axial force of the segment lining occurs mainly in the range of $\pm 90^{\circ}$ at the arch bottom, and the maximum value reaches $71.5 \mathrm{kN}$. It can be seen from Fig. 6 (b) that the axial force value within the range of $\pm 45^{\circ}$ of the right arch waist of the tunnel increases compared with Fig. 6 (a), which is due to the influence of the excavation of the right line tunnel. It can be seen from Fig. 7 (a) that the polar coordinates of the bending moment show a symmetrical relationship. The larger bending moment occurs in the range of $\pm 30^{\circ}$ of the arch waist of the segment lining and the maximum value is $16.8 \mathrm{kN} . \mathrm{m}$, while the smaller bending moment of the segment lining occurs in the range of $\pm 60^{\circ}$ of the arch top and bottom of the tunnel and the minimum value is $-2.96 \mathrm{kN}$.m. It can be seen from Fig. 7 (b) that the polar coordinate graph of bending moment presents an asymmetry. The bending moment of the left and right arch waist decreases to different extent and the maximum value decreases to $12.1 \mathrm{kN}$.m, while the bending moment in the range of $45^{\circ}$ (take anticlockwise as positive) at the arch top and $-45^{\circ}$ at the arch bottom increases, which is closely related to the excavation of the right line tunnel.

\subsection{Stress field analysis}

TBM construction will cause additional stress and deformation for existing buildings. It is significant to know well the overall stress state of the existing structures and analyze their safety during TBM tunnelling. Figure $8 \sim 10$ show the stress of strata, building and segment structure of tunnel under different construction stages.

It can be seen from Fig. 8 that the stress of each stratum during TBM tunnelling always increases with depth in different construction stages. The bending phenomenon of stress isoline begins to appear within 
one time of diameter above the tunnel, and the bending degree increases as the tunnelling proceeds. TBM tunnelling results in stress redistribution in the stratum and the surrounding rock near the arch waist of the tunnel is the main disturbance area, and stress concentration phenomenon occurs. The stress near arch waist is higher than other positions in the same depth, which is compressive stress. Its maximum value occurs at construction stage 6 , about $1.44 \mathrm{MPa}$. And the stress in the vicinity of tunnel arch vault and arch bottom is lower than that of other positions in the same depth, which is still compressive stress. This is due to the obvious release of internal stress in the bottom and top of the tunnel caused by TBM excavation, which becomes the weak part of surrounding rock stability. The lining segment undertakes the part of released stress of surrounding rock, and at the same time produces some deformation near the arch bottom and arch top of the tunnel to make the vertical stress concentrate on the arch waist.

\subsection{Analysis of displacement field}

The spatial graphs of ground settlement after excavation of the left and right tunnels are shown in Fig. $11(a)$ and (b) respectively. It is more intuitive to observe that during the construction of TBM tunnel, ground settlement groove along the transverse and vertical sections occurs near the building and tunnels, and the settlement becomes smaller with the farther the distance from the building and tunnels. The maximum ground settlement values of after completions of left and right tunnel are $6.52 \mathrm{~mm}$ and 7.96 $\mathrm{mm}$ respectively.

The ground settlements of observation sections (Cross Sect. $1 \sim 3$ ) under different construction stages are plotted in Fig. 12. The ground settlement curve changes dynamically along the cross section and is approximately V-shaped. The width of the ground settlement groove is about 5-6 times of diameter of the tunnel, and the ground building is within this range. The position corresponding to the maximum value of ground settlement for each observation section deviates due to the influence of the building during different excavation stages.

Figure 12 (a), (c) and (e) show the ground settlements of each cross section under construction stage $1 \sim$ 3 (left line tunnel construction). The settlement values of cross Sect. $1 \sim 3$ presents an increasing trend as the tunnel is excavated deeper, for instance, the surface settlement of cross Sect. 2 in the construction stage 2 shows a certain degree of increase relative to the previous stage, and the increased value of maximum settlement is about $1.45 \mathrm{~mm}$. After the construction stage 3 , the surface settlement curves of cross Sect. 3 and cross Sect. 1 are similar, and the maximum ground settlement value of each cross section is $3.38 \mathrm{~mm}, 6.5 \mathrm{~mm}$ and $3.2 \mathrm{~mm}$ respectively.

Figure 12 (b), (d) and (f) are the ground settlements of each cross section under the construction stages $4 \sim 6$ (right line tunnel construction). The ground settlement curve of the same cross section changes obviously. Both the range of settlement groove and the settlement amount increase and the symmetrical axis of the settlement curve shifts to the right as excavation proceeds. The surface settlement curves at cross Sect. 1 and 3 are approximately similar when double-line tunnel construction is completed, as shown in Fig. 12 (f). And the maximum surface settlement value at cross Sect. 1 and 3 is much less than that at cross Sect. 2. This is because cross Sect. 2 is located beneath the building, and its surface 
settlement is greatly affected by the building during tunnel excavation. Therefore, special attention should be paid to the influence of the tunnel excavation under existing buildings.

\section{Conclusions}

Based on the section engineering of Qingdao Metro Line 1, the ground settlement characteristics, differential settlement and the stress distribution of the existing building and the stress of segment structure have been analyzed combined the three-dimensional numerical simulation and site monitoring for TBM excavation crossing the existing building. The conclusions are drawn as follows:

(1) The stress of each stratum during TBM tunnelling increases with depth in different construction stages. TBM tunnelling results in stress redistribution in the stratum, the surrounding rock near the arch waist is the main disturbance area and stress concentration phenomenon occurs.

(2) The settlement of the surface building presents an increasing trend during the excavation beneath it. The comparison of ground settlement between measured and simulated values verifies the numerical modelling. The settlement of the surface building caused by TBM tunnelling meets the control standard of "Code for Design of Building Foundation (GB50007-2011)".

(3) During excavation, for the segment structure, the maximum principle tensile stress occurs inside the arch bottom of the tunnel, while the maximum principle compressive stress occurs near the arch top and arch waist, with obvious stress concentration. For the surface building, the maximum principle tensile stress occurs at the door opening of the wall on the first floor and the maximum principle compressive stress is at the corner of wall. They are less than the tensile and compressive strength of the segment structure and building respectively, and have enough safety margins.

(4) When TBM double-line tunnelling crosses the existing building, ground settlement groove along the transverse and vertical sections occurs near the building and tunnels, and the settlement becomes smaller with the farther distance from the building and tunnels. The ground settlement curve on some cross section changes dynamically and is approximately V-shaped, and the width of the ground settlement groove is about $5 \sim 6$ times of tunnel diameter. For the same cross section, the range of the settlement groove after tunnelling right line increases obviously compared with that after tunnelling left line, the settlement values also increase, and the symmetrical axis of the settlement curve is shifted to the right.

\section{Declarations}

\section{Acknowledgements}

This work was financially supported by National Natural Science Foundation of China (Grant No. 52078108). 


\section{References}

[1] Zhang Xiao, Ding Zhi, Wu Yunshuang et al. Analysis on present situation and prospects of city rail traffic development[J]. Modern Cities, 2014, 9(2): 17-19. (in Chinese)

[2] Lin Gang, Shi Xuantao, Chen Jun. Application and practice of double-shield TBM to Qingdao rail transit tunnel [J]. Tunnel Construction, 2019, 39(12): 2020-2029. (in Chinese)

[3] Wu Fengbo, Jin Huai, Shang Yanjun et al. Study of building/structure settlement prediction method surrounding urban rail transit tunnel engineering [J]. Chinese Journal of Rock Mechanics and Engineering, 2013, 32(S2): 3535-3544. (in Chinese)

[4] Tong Liyuan, Zhang Defu, Yu Wei et al. Deformation behavior analysis on new tunnel passing below the existing subway tunnel [J]. Chinese Journal of Underground Space and Engineering, 2013(9): 1940-1944. (in Chinese)

[5] Xie X Y, Wang Q, Isam S. A real-time interaction platform for settlement control during shield tunnelling construction[J]. Automation in Construction, 2018, 94(10): 154-167.

[6] Meng Fanyan, Chen Renpeng, Kang Xin. Effects of tunneling-induced soil disturbance on the postconstruction settlement in structured soft soils[J]. Tunnelling and Underground Space Technology incorporating Trenchless Technology Research, 2018, 80(10):53-63.

[7] Jiang Bo. Surrounding buildings influence law under the condition of subway construction used by shallow tunneling method [J]. Journal of Liaoning Technical University (Natural Science), 2016, 35(5):484-487. (in Chinese)

[8] Xiao Bo, Wang Jianhua, Zhu Renjing. Influence of tunnel excavationon existing buildings in mountainous city[J]. Chinese Journal of Underground Space and Engineering, 2017, 13(S1): 365-372. (in Chinese)

[9] Liu Nianwu, Chen Yitian, Gong Xiaonan, et al. Analysis of deformation characteristics of foundation pit of metro station and adjacent buildings induced by deep excavation in soft soil[J]. Rock and Soil Mechanics, 2019, 40(4): 1515-1525 +1576. (in Chinese)

[10] Peck R B. Deep Excavations and Tunneling in Soft Ground[C]. Proc. of 7th ICSMFE, Mexico, 1969: 225-290.

[11] Chen Chunlai, Zhao Chengli, Wei Gang, et al. Prediction of soil settlement induced by double-line shield tunnel based on Peck formula[J]. Rock and Soil Mechanics, 2014, 35 (8): 2212-2218. (in Chinese)

[12] Wei Gang, Zhou Yangkan. A simplified method for predicting ground settlement caused by adjacent parallel twin shield tunnel construction based on stochastic medium theory[J]. Rock and Soil Mechanics, 2016,37 (S2): 113-119.(in Chinese) 
[13] Mroueh $\mathrm{H}$, Shahrour I. A full 3-D finite element analysis of tunnelling-adjacent structures interaction[J]. Computers \& Geotechnics, 2003, 30(3): 245-253.

[14] Jiang Xinliang, Jia Yong, Zhao Baojian et al. Analysis of influence of metro tunnel construction on adjacent buildings[J]. Rock and Soil Mechanics, 2008, 29(11): 3047-3052. (in Chinese)

[15] Jiang Xiaoting , Lu Ping, Zheng Gang et al. Influences on surface structure induced by shield tunneling in Tianjin soft ground area[J]. Rock and Soil Mechanics, 2014, 35(S2): 535-542. (in Chinese)

[16] Jenck O, Dias D. 3-D finite difference analysis of the interaction between concrete building and shallow tunnelling[J]. Géotechnique, 2004, 54(8): 519-528.

[17] Zhang Dingli, Li Pengfei, Hou Yanjuan, et al. Influence due to urban tunnel excavation on ground buildings and its countermeasures[J]. Chinese Journal of Geotechnical Engineering, 2010, 32(2): 296302. (in Chinese)

[18] Shen Xingzhu, Gao Feng, Wang Shaopeng, et al. Research on Influence of Shield Tunnel Construction on Buildings with Shallow Foundations[J]. Construction Technology, 2017, 46(13): 132137. (in Chinese)

[19] Zhang Wenting, Wang Fei, Wang Chongge, et al. Dynamic study on coupling characteristics between ground surface and building of Qingdao Metro Line 3[J]. Journal of Guangxi University (Natural Science Edition), 2019, 44 (2): 486-494. (in Chinese)

[20] Lu Ping, Geng Yan, Zhang Wenjun, et al. Study of Influence of Crossing Mode of Parallel Tunnels on Deformation of Masonry Buildings[J]. Tunnel Construction, 2019, 39 (1): 60-67. (in Chinese)

[21] Qiu Mingming, Yang Guolin, Jiang Anlong, et al. Numerical analysis of stratum deformation induced by tunnel boring machine construction for metro[J]. Journal of Shenzhen University (Science and Engineering), 2016, 33(4):377-387. (in Chinese)

[22] Liu Junsheng, Lu Jinfang, Xu Dongdong. Influence of Grouting Pressure on the Surface Settlement of Shield Tunnel[J]. Urban Geotechnical Investigation \& Surveying, 2019, (5): 180-185. (in Chinese)

\section{Figures}




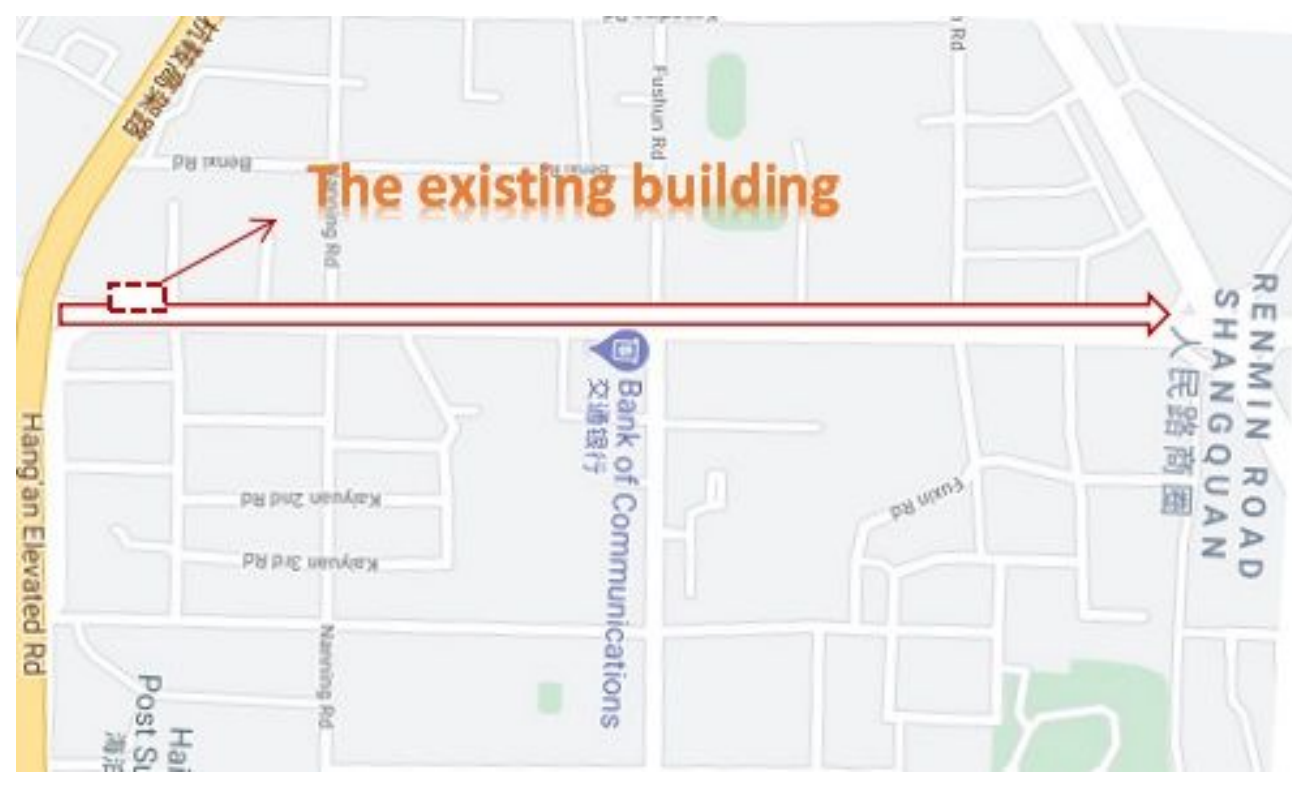

Figure 1

General layout of tunnel between Haiboqiao station $~$ Xiaocunzhuang station

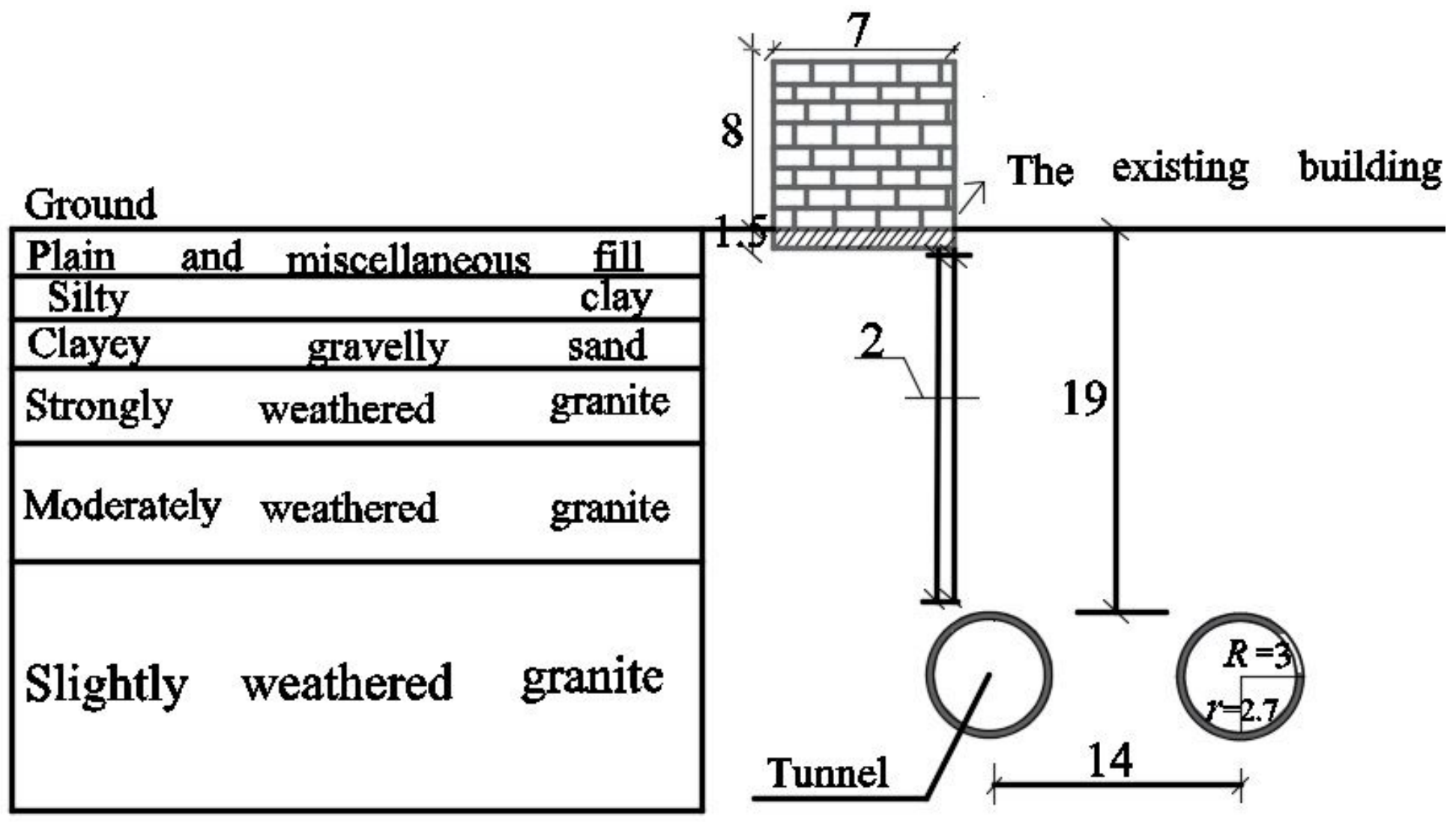

Figure 2

The tunnel-house location and stratum distribution (Unit: $\mathrm{m}$ ) 


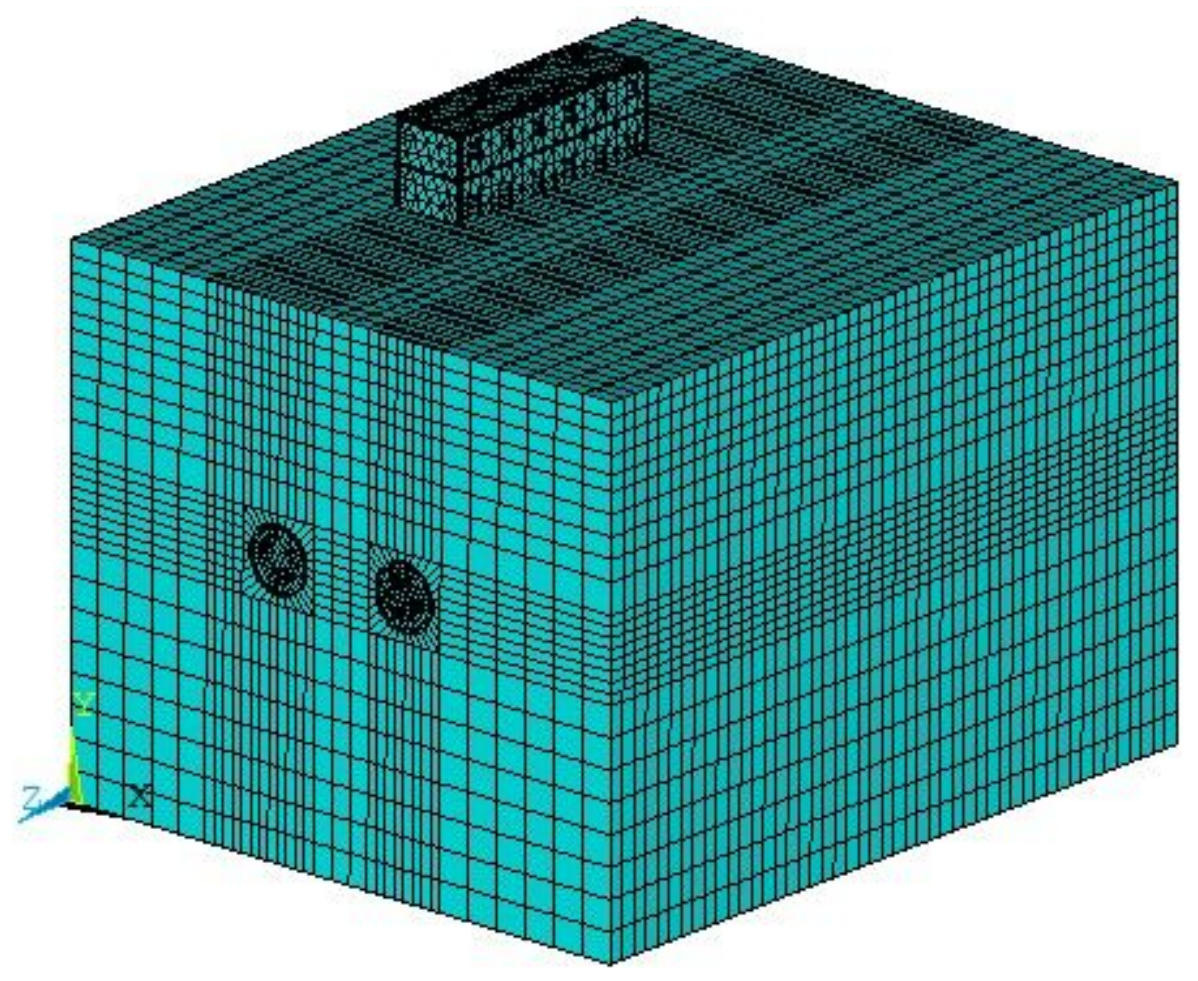

Figure 3

Computational model 


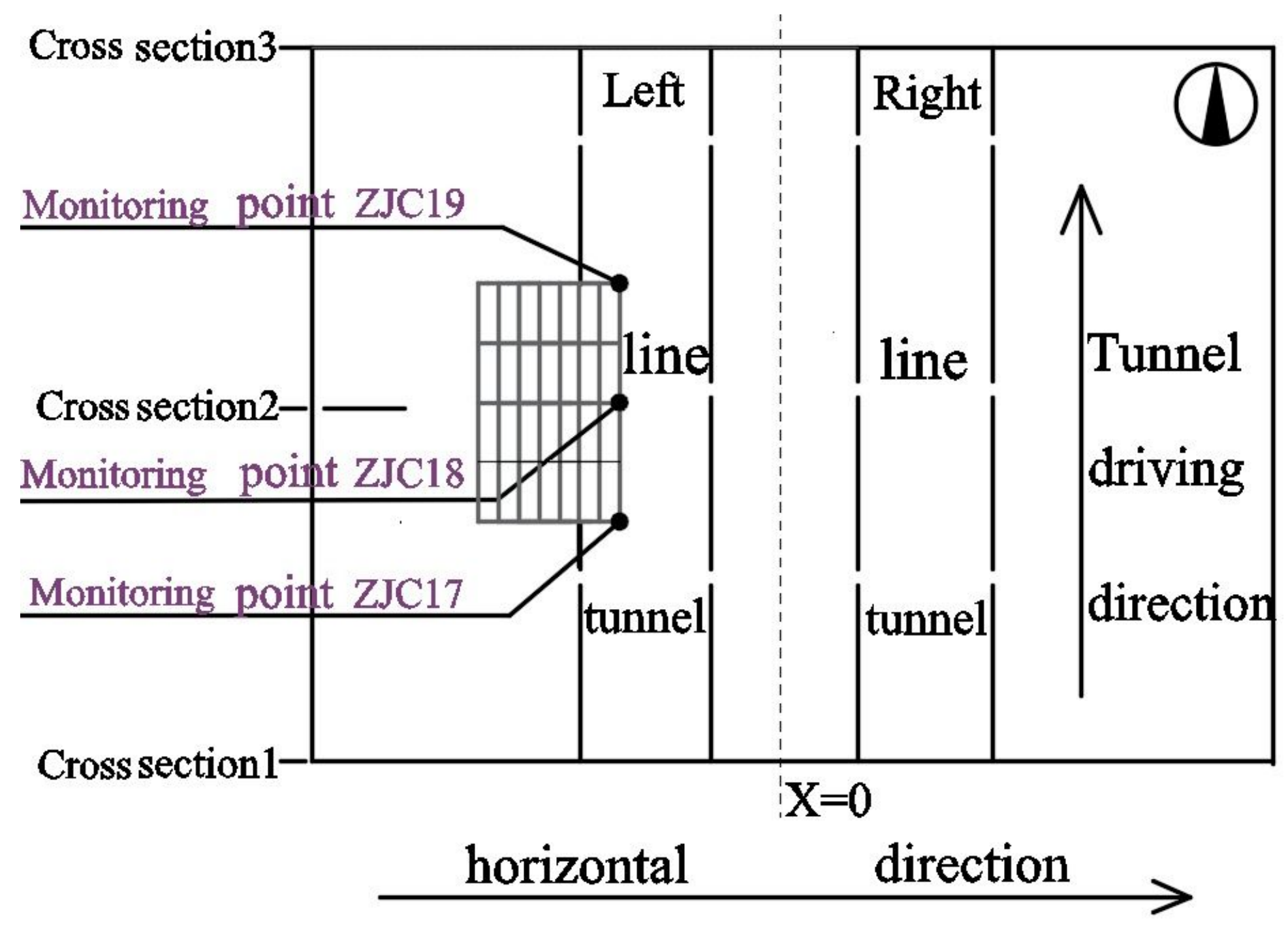

Figure 4

Location of monitoring points around building, tunnels and cross sections 


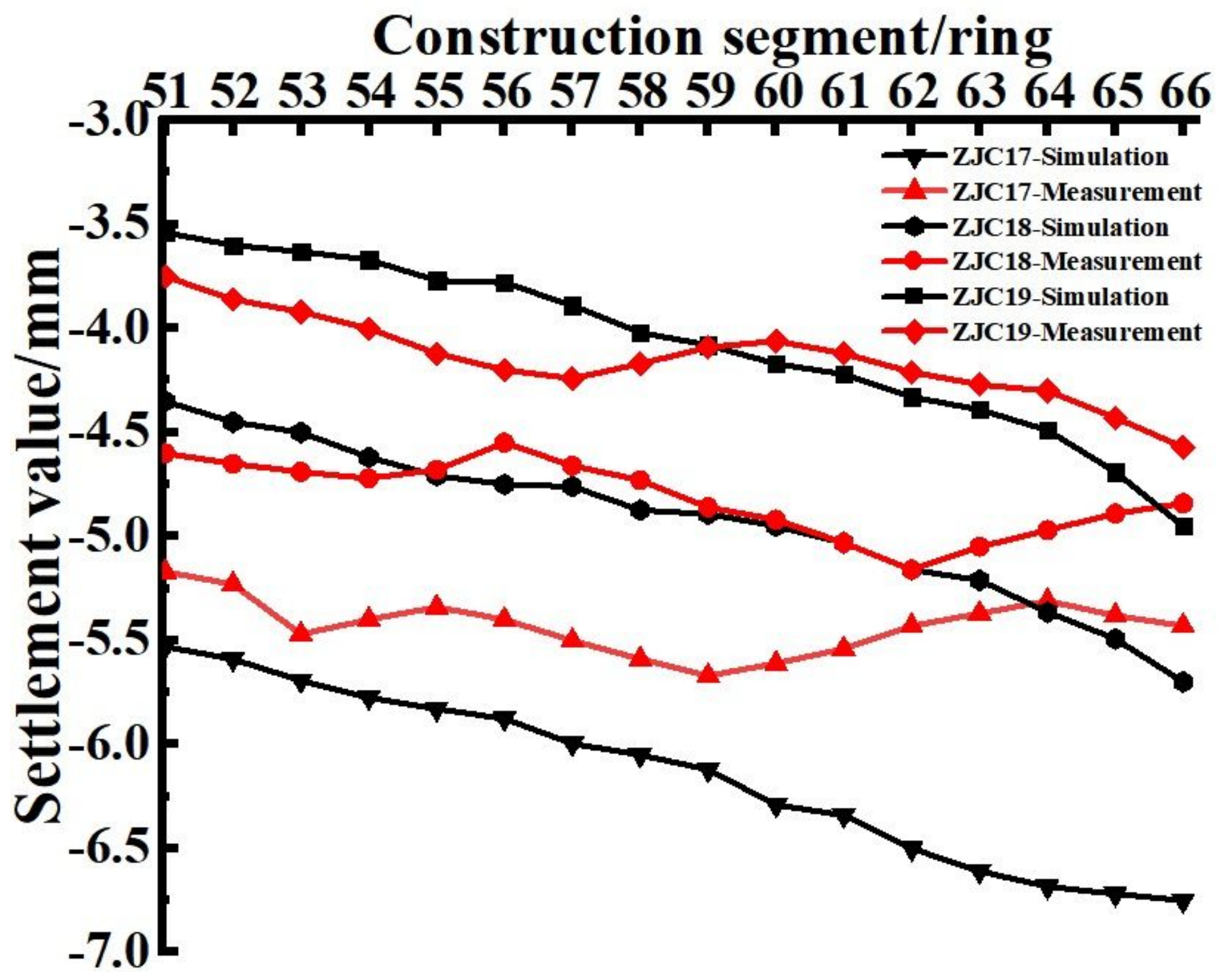

Figure 5

Comparison of measured and simulated settlement values at each monitoring point 


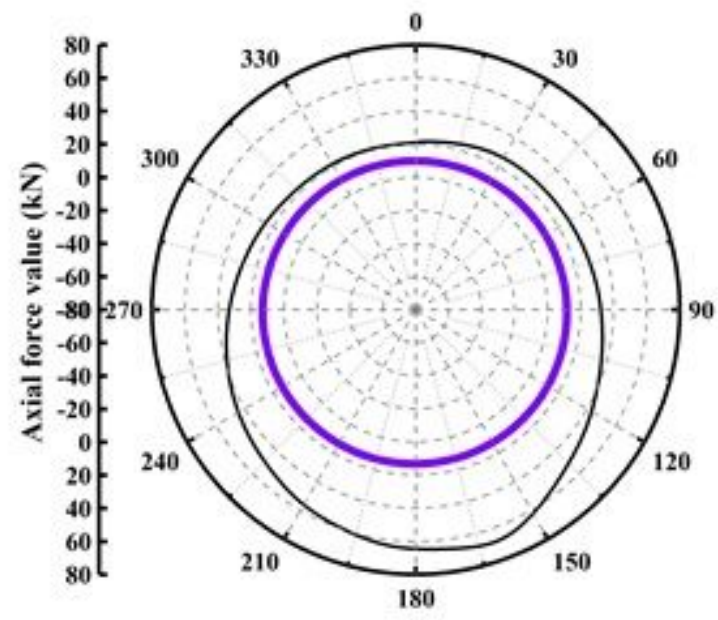

(a) After completion of left tunnel

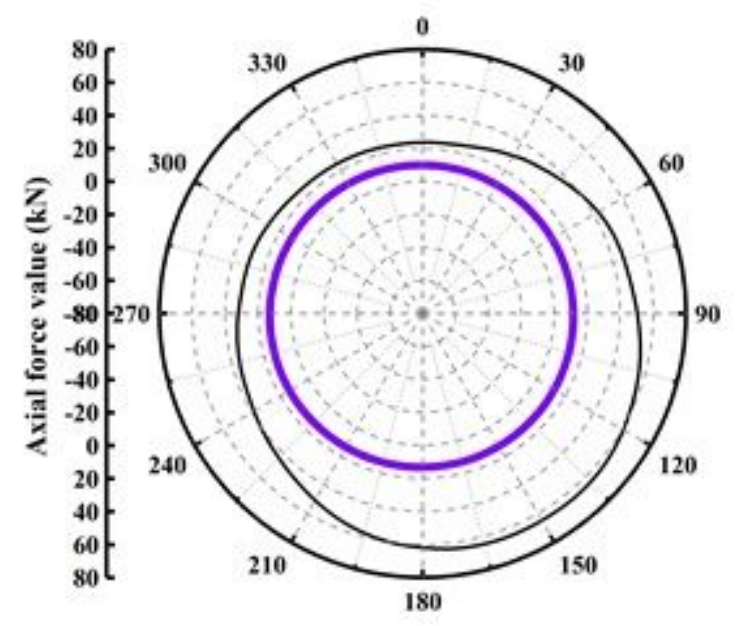

(b) After completion of right tunnel

Figure 6

Axial force of segment lining at cross section 2

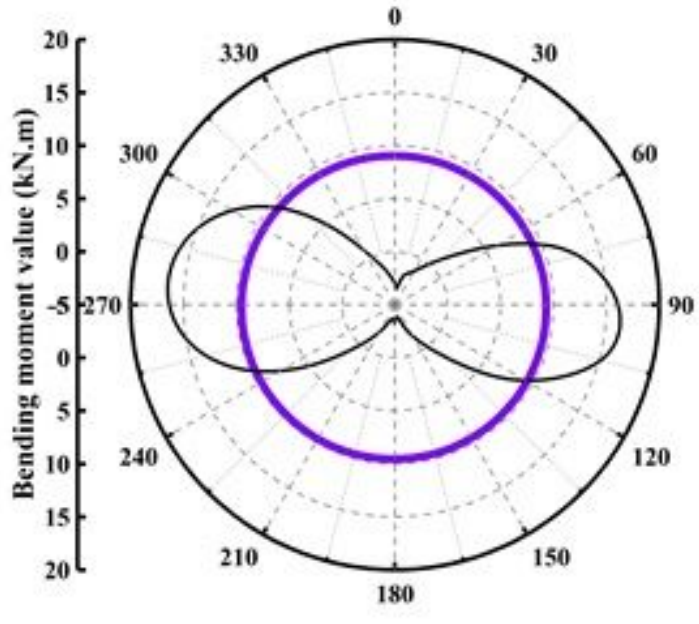

(a) After completion of left tunnel

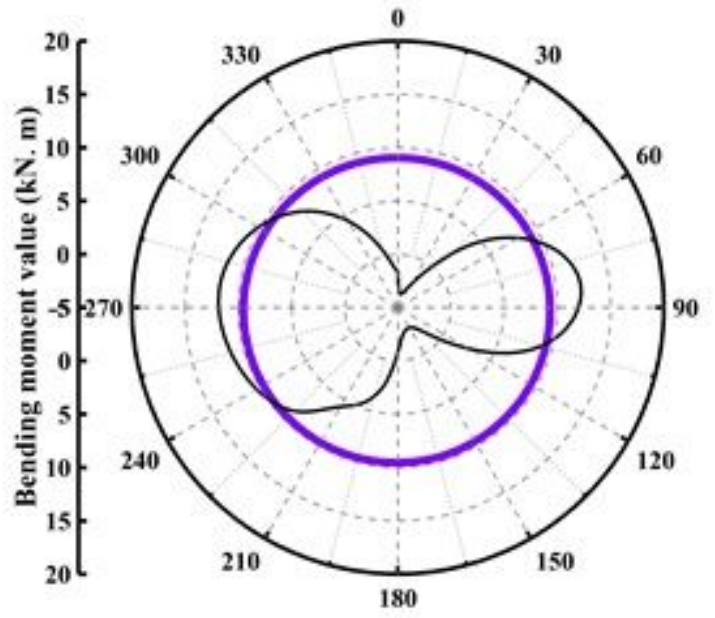

(b) After completion of right tunnel

Figure 7

Bending moment of segment lining at cross section 2 

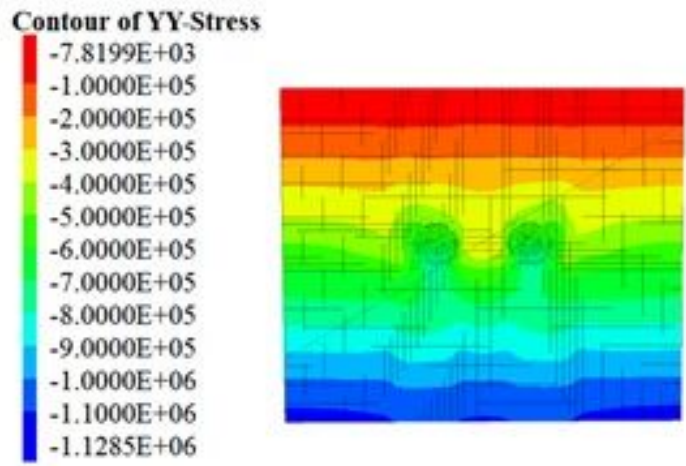

(a) construction stage 1

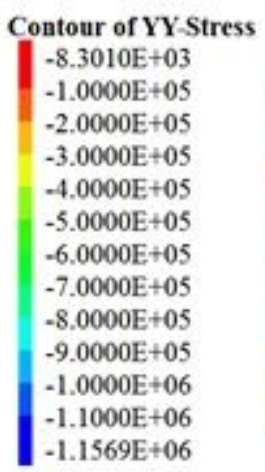

(c) construction stage 2

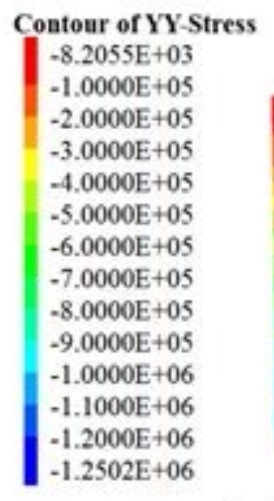

(e) construction stage 3

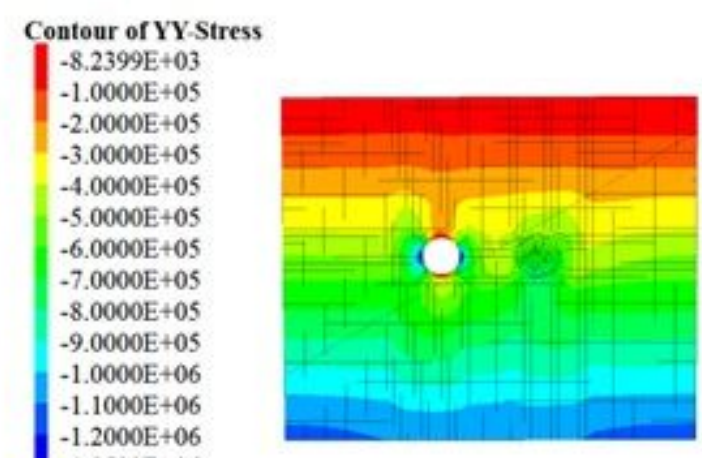

(b) construction stage 4

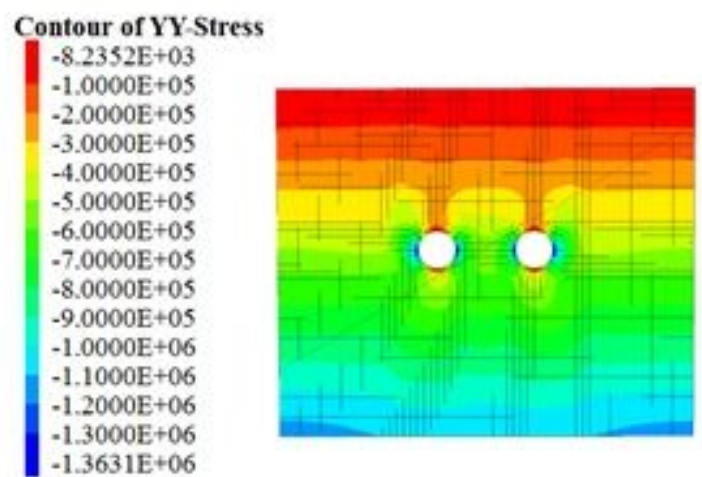

(d) construction stage 5

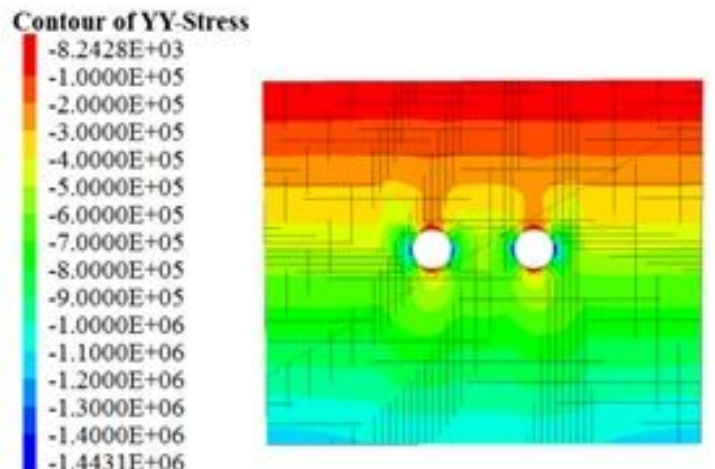

(f) construction stage 6

\section{Figure 8}

Vertical stress nephogram of cross section 2 under different construction stages

Conteur of Mar. Principal Sil
$2.2078 \mathrm{E}+06$
$2.2000 \mathrm{E}+06$
$2.0000 \mathrm{E}+06$
$1.8000 \mathrm{E}+06$
$1.6000 \mathrm{E}+06$
$1.4000 \mathrm{E}+06$
$1.2000 \mathrm{E}+06$
$1.0000 \mathrm{E}+06$
$8.0000 \mathrm{E}+05$
$6.0000 \mathrm{E}+05$
$4.0000 \mathrm{E}+05$
$2.0000 \mathrm{E}+05$
$0.0000 \mathrm{E}+00$
$-1.8852 \mathrm{E}+05$

(a) Completion of left line excavation

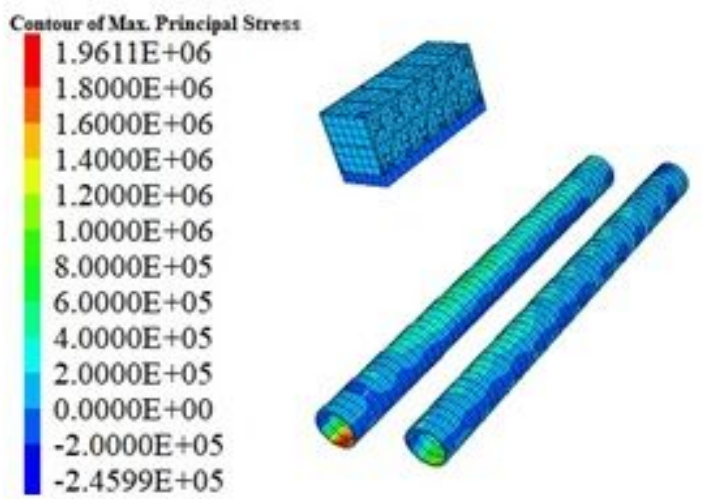

(b) Completion of right line excavation 
Figure 9

The maximum principle stress nephogram of the building and segment structure

Contour of Min. Principal Stre
$8.3103 \mathrm{E}+04$
$0.0000 \mathrm{E}+00$
$-2.5000 \mathrm{E}+05$
$-5.0000 \mathrm{E}+05$
$-7.5000 \mathrm{E}+05$
$-1.0000 \mathrm{E}+06$
$-1.2500 \mathrm{E}+06$
$-1.5000 \mathrm{E}+06$
$-1.7500 \mathrm{E}+06$
$-2.0000 \mathrm{E}+06$
$-2.2500 \mathrm{E}+06$
$-2.5000 \mathrm{E}+06$
$-2.7500 \mathrm{E}+06$
$-3.0000 \mathrm{E}+06$
$-3.2500 \mathrm{E}+06$
$-3.3575 \mathrm{E}+06$

(a) Completion of left line excavation

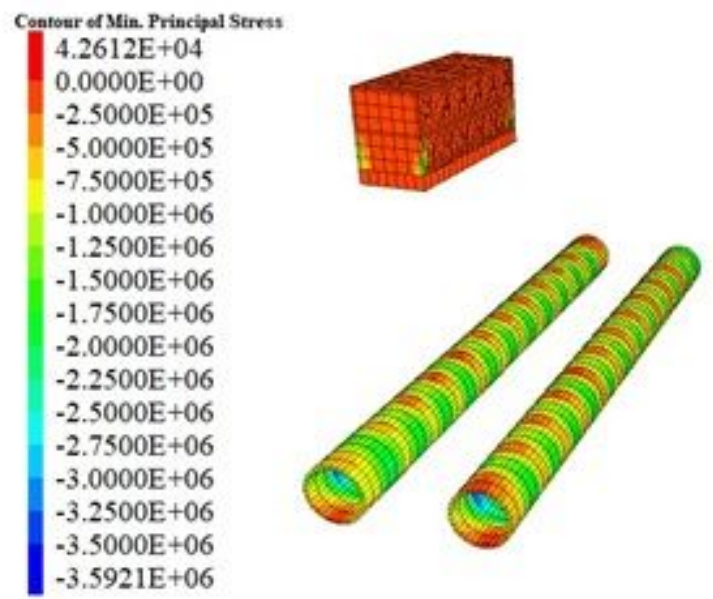

(b) Completion of right line excavation

\section{Figure 10}

The minimum principle stress nephogram of the building and segment structure

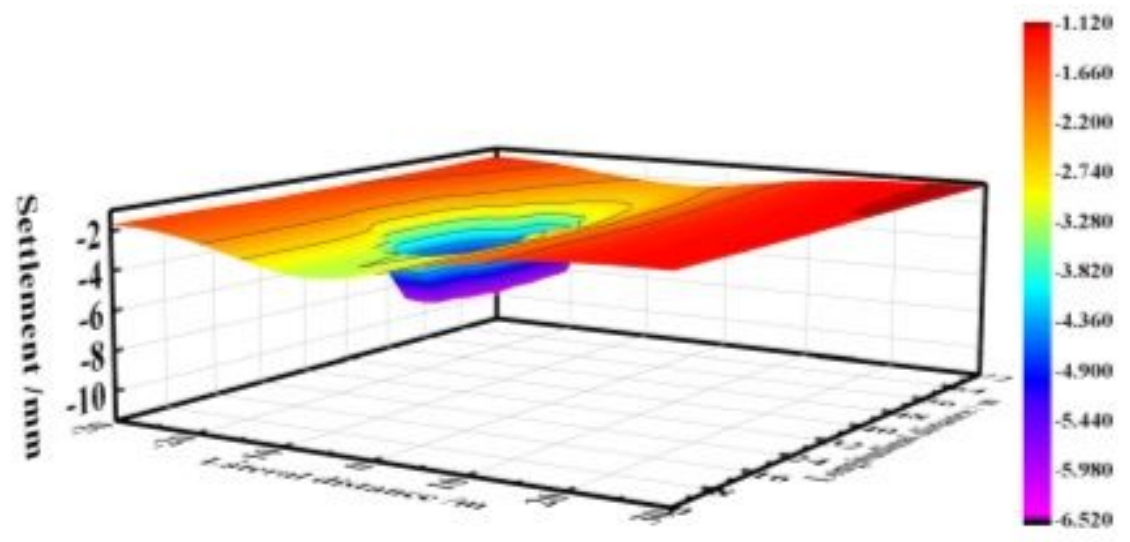

(a) After completion of left tunnel

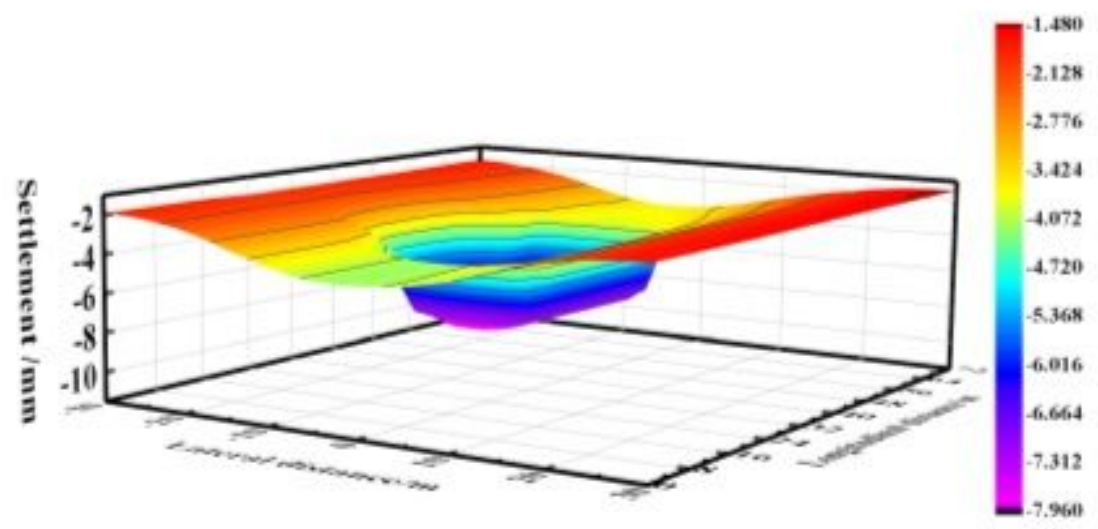

(b) After completion of right tunnel

\section{Figure 11}




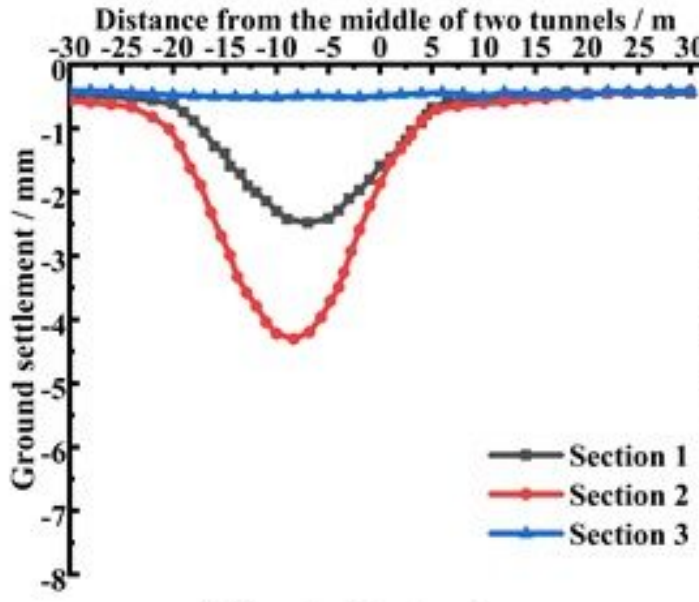

(a) Construction stage 1

Distance from the middle of two tunnels / $m$

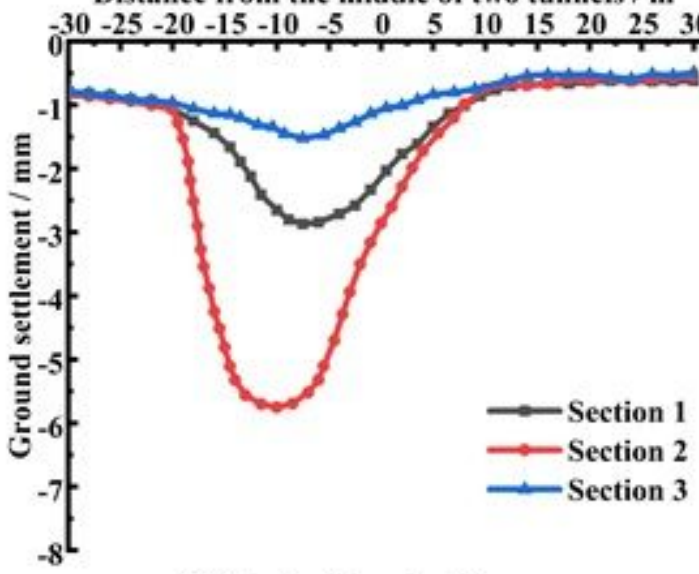

(c) Construction stage 2

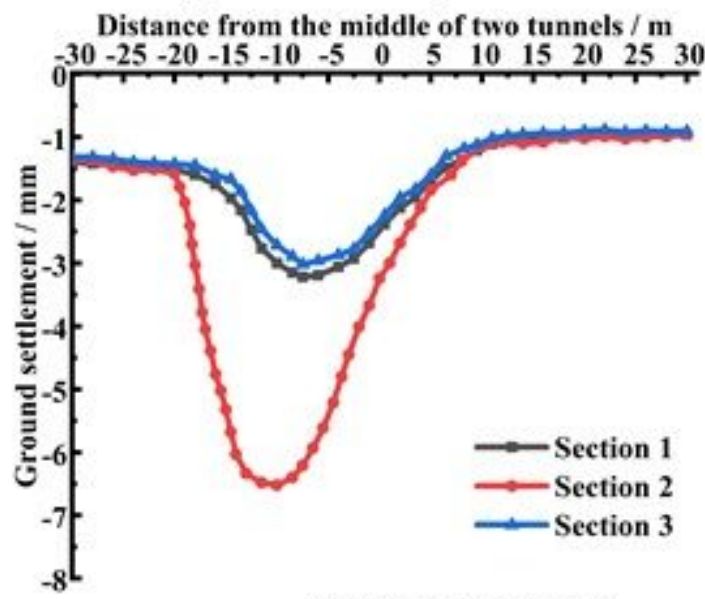

(e) Construction stage 3
Distance from the middle of two tunnels / $\mathrm{m}$

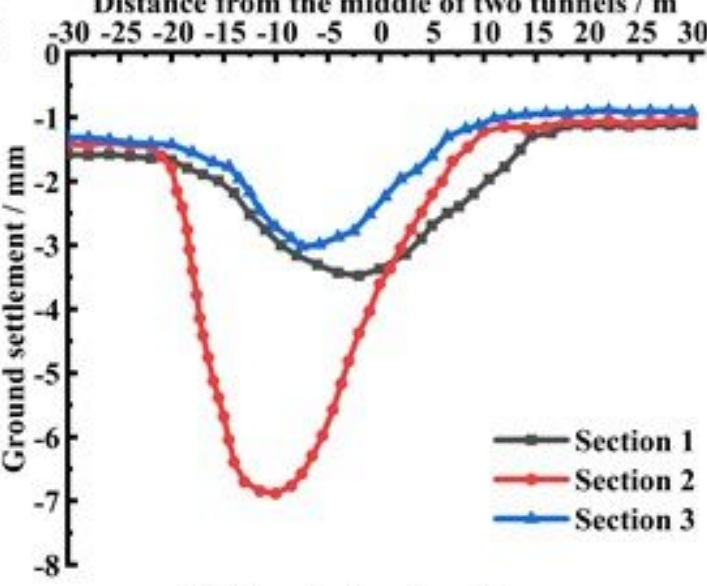

(b) Construction stage 4

Distance from the middle of two tunnels / $\mathrm{m}$

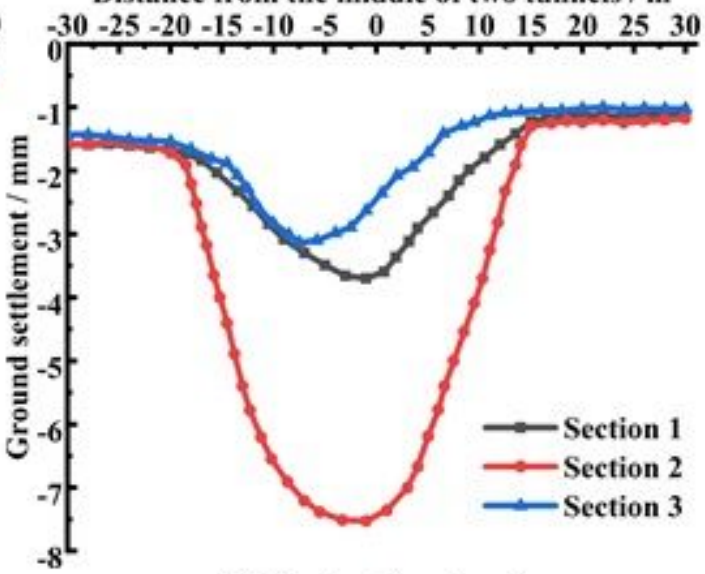

(d) Construction stage 5

Distance from the middle of two tunnels / $\mathrm{m}$

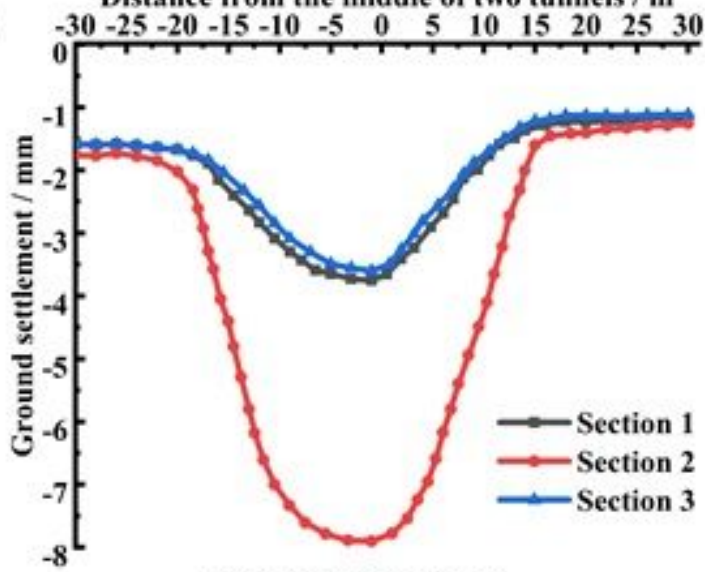

(f) Construction stage 6

Figure 12

The curves of ground settlement along cross-section under different construction stages 